\title{
Testing for the survey mode effect on contingent valuation data quality: A case study of web based versus in-person interviews
}

\author{
Cristina Marta-Pedroso ${ }^{a, b, *}$, Helena Freitas ${ }^{a}$, Tiago Domingos ${ }^{b}$ \\ ${ }^{a}$ Department of Botany, University of Coimbra, Calçada Martim de Freitas, 3001-455 Coimbra, Portugal \\ ${ }^{b}$ Environment and Energy Section, DEM, Instituto Superior Técnico, Avenida Rovisco Pais, 1, 1049-001 Lisboa, Portugal
}

\section{A R T I C L E I N F O}

Article history:

Received 31 January 2006

Received in revised form

22 November 2006

Accepted 8 February 2007

Available online 26 March 2007

Keywords:

Contingent valuation

Survey mode effect

Internet

Validity

\begin{abstract}
A B S T R A C T
This paper addresses the lack of empirical evaluation of the use of web based surveys in the context of contingent valuation surveys. We compare, using a case study, in-person interviews with web based surveys regarding response rate, information additivity effects and respondents' attitudes towards paying. The web based survey had a much lower response (5.1\%) than the in-person interviewing (84\%). We find the web based contingent valuation surveys to be neither more susceptible to information additivity effects nor more prone to zero protest responses. We conclude in favor of the use of web based surveys, namely in Portugal, where the number of Internet users is rapidly increasing, although further research efforts are required on their use.
\end{abstract}

(c) 2007 Elsevier B.V. All rights reserved.

\section{Introduction}

The contingent valuation method (CVM) is a stated preference method $^{1}$ for valuing changes in the provision of nonmarketable goods (e.g. environmental amenities).

The method was conceptually proposed by CiriacyWantrup in 1947, but the first empirical application only took place in 1961 with Robert Davis, in the US (Jackobsson and Dragun, 1996; Venkatachalam, 2004). The contingent valuation method rose to high prominence in the 1980s and in the last two decades has been routinely used in the appraisal of projects with impact on the environment. Its potential to capture both use and non-use values of environmental assets and the flexibility of its application largely contributed to its massive use (Carson, 2000).

Basically, CVM is a survey-based methodology which relies on obtaining monetary estimates for the economic value of a specified change in the provision of the environmental good of interest, which typically is not traded in the conventional markets. Hence CVM application consists in the construction of hypothetical markets (also called elicitation scenarios) where the individuals' valuation of the good is elicited. Monetary estimates are obtained either as individuals' Willingness to Pay (WTP) or Willingness to Accept (WTA). WTP measures the amount of income a person is willing to forego in exchange for an improved state of an environmental good.

\footnotetext{
* Corresponding author. Environment and Energy Section, DEM, Instituto Superior Técnico, Avenida Rovisco Pais, 1, 1049 - 001 Lisboa, Portugal. Tel.: +351 21 8419439; fax: +351 218417365.

E-mail address: cristina.marta@ist.utl.pt (C. Marta-Pedroso).

${ }^{1}$ Stated preference, or direct, methods employ constructed markets in an experimental setting to elicit individuals' preferences. Other stated preference valuation approaches include contingent ranking, contingent choice and conjoint analysis (see Boxall et al., 1996, for a comprehensive comparison of the various stated preference approaches).
} 
For example, it measures what fraction of their income people would be willing to spend to preserve an endangered species or a unique ecosystem. Correspondingly, WTA estimates the compensation that would be required for people to accept its loss. Although widely used, CVM is not exempt of criticisms. The controversy surrounding its application is often dominated by the effect of survey mode on individuals' valuation, i.e. the effect of interview methods used to introduce individuals to the hypothetical market. Typically, a mail questionnaire or a telephone or in-person interview has been used to convey the proposed transaction.

With the advent of the Internet the use of web based stated preferences surveys emerged in the fields of sociological and marketing research. However, their use is still largely restricted to these fields. Schonlau et al. (2001) present a summary of 65 studies, undertaken between 1992 and 2001, in which the Internet was used to deliver the surveys.

Although a promising means for conducting survey-based research, the use of the Internet and electronic mail for delivering contingent valuation surveys is just emerging and there are few published references reporting on its use in this context (Berrens et al., 2004; Tsuge and Washida, 2003; Arlinghaus and Mehner, 2004; Hudson et al., 2004; Lenert, 2003). None of the existing Internet based contingent valuation studies focused on data quality evaluation or data comparability with other survey modes.

The lack of empirical evaluation of the use of web based surveys in environmental economic valuation is addressed in this paper. Although the web based surveys are appealing for the CVM practitioner because a large number of individuals can be reached at low costs, the in-person interviewing survey mode is often mentioned as the proper survey mode in the context of contingent valuation (instead of being highly costly as discussed below in Section 2). Thus there is a need to test whether respondents interviewed through the Internet behavior differ from those interviewed personally.

The following criteria were used for our evaluation purposes: survey response rate, information additivity effects, and respondents' attitude towards paying.

The paper is organized as follows. In the next section, we compare advantages and disadvantages of both survey modes in contingent valuation. In Section 3 we present the research context and the methodological framework. Results and discussion of the empirical research are presented in Section 4 . In the last section of the paper the main conclusions of our research are summarized.

\section{In-person interviews and web based questionnaires: advantages and disadvantages for their use in the administration of contingent valuation surveys}

In-person interviews are the method recommended by the $\mathrm{NOAA}^{2}$ panel for the administration of contingent valuation surveys. The panel argued that this survey method allows for

\footnotetext{
${ }^{2}$ After the Exxon Valdez oil spill (1989), the largest oil spill in the USA history, the National Oceanic and Atmospheric Administration (NOAA), in response to criticisms on the use of contingent valuation surveys, convened a panel of experts led by Nobel Prize laureates Kenneth Arrow and Robert Solow to review the use of CVM in environmental damage assessment.
}

the presentation of more complex information since photos, maps and other visual supports may be used. Face-to-face interviews also allow for a better assessment of how well respondents have understood the context and elicitation scenarios used (Arrow et al., 1993; Jackobsson and Dragun, 1996). Also, a lower rate of non-response has been reported as compared with other delivery methods, namely phone and mail surveys ${ }^{3}$ (Mannesto and Loomis, 1991).

Common arguments against the use of the in-person interviews method are that surveys are too expensive, and may be susceptible to "interviewer effects" that can bias the survey results. Interviewer effects on WTP estimates have been reported by different authors. Leggett et al. (2003) found that in-person interviews provide higher WTP estimates than self-administered surveys. Bateman and Mawby (2004) and Loureiro and Lotade (2005) provided evidence of WTP estimates' sensitivity across different interviewers. Another drawback of in-person interviews is that the interviewing time may not allow respondents to fully understand the valuation context and frame it in the context of their individual preferences (Macmillan et al., 2002).

Internet surveys exhibit some of the advantages of the conventional mail ones, such as providing respondents with some privacy and plenty of time to think about the proposed transaction. Other inherent advantages of using Internet based surveys include lower cost (postage, printing, interviewer and transcription costs are avoided) and can be administered rapidly (Hudson et al., 2004; Kaplowitz et al., 2004). Also, Internet surveys are distinct from all the other types of surveys because respondents' answers can be directly downloaded into a database, avoiding not only transcription costs but also transcription errors (Fricker and Schonlau, 2002).

Internet surveys also have serious problems, including sample selectivity and sample representativeness. These derive from the fact that not everybody has Internet access, and those who do have may not feel comfortable transmitting personal information through the Internet, and from the current absence of a procedure analog to the random digit dialing (RDD) method ${ }^{4}$ used for telephone surveys (Schaefer and Dillman, 1998; Hudson et al., 2004)

\section{Methodology}

Using as a case study the preservation of the Cereal Steppe of Castro Verde, we designed an experiment to test the use of web based surveys versus in-person interviewing in the context of contingent valuation. Questionnaire design, sampling procedure and survey protocol are described later in this section.

\subsection{The case study}

The cereal steppe of Castro Verde is the main landscape unit within the Municipality of Castro Verde, Southern Portugal. It is a mosaic landscape, consisting mainly of cereal fields,

\footnotetext{
${ }^{3}$ Since in-person interviewing is highly costly its comparison with other modes has been restricted to a very few studies. Also, very often, in-person interviews based studies do not report nonresponse rates which would allow quantitative comparisons.

${ }^{4}$ RDD provides a way of reaching unlisted telephone numbers and thus facilitates defining probability.
} 
stubble, ploughed and fallow land (usually used as pastures) and is based on extensive cultivation of cereals in a rotation scheme.

Although marginal, with yields less than half the average yield in the European Union (Suárez et al., 1997), the importance of this human dominated landscape, as one of the last refuges for many steppic birds, such as the great bustard (Otis tarda L.), the little bustard (Tetrax tetrax L.), and the lesser kestrel (Falco naumanni Fleischer) is widely recognized (Tucker and Heath, 1994; Delgado and Moreira, 2000).

In 1995 a management program for this landscape (Zonal Program of Castro Verde) was implemented within the European Union's Agri-environmental Measures. The program aimed primarily at the protection of bird species and landscape maintenance by compensating farmers financially for maintaining the described farming practice.

\subsection{The contingent valuation scenarios}

In this study, the contingent valuation method involved asking individuals about their willingness to pay for preserving the Cereal Steppe of Castro Verde, assuming a hypothetical situation in which the current EU financial support for keeping farmers' income was to be suspended. In this context, two alternative management options to maintain the current landscape structure, generated by the traditional cultivation of cereals, were set (Appendix A). One of the management scenarios introduced to respondents was based on government intervention, and therefore, individuals were asked to state their WTP to preserve the landscape, as an annual governmental tax, additional to the existing ones. The other hypothetical management scenario presented to respondents was an intervention led by a non-profit organization supported by citizens' donations. In this case individuals were asked for their WTP as a one time payment - a donation. The inclusion of two distinct management scenarios in the contingent valuation questionnaire was meant to minimize payment vehicle effects, or, stated differently, to minimize the probability of respondents' attitude towards paying being influenced by the nature of the payment mechanisms offered. Moreover, the scenarios presented to respondents were formulated to be as realistic as possible. One of the contingent valuation scenarios introduced to respondents referred to a government intervention and the other one comprised the intervention of an NGO. The first one, the government intervention, is naturally expectable from a citizen's perspective regarding the provision of public goods. The management scenario that comprises the intervention of an NGO tried to mimic the recent past intervention of the more well established Portuguese non-governmental environmental organization (LPN - The League for Nature Protection) in the study area. LPN acquired farms in the Municipality Castro Verde, which were at risk of conversion to Eucalyptus plantations. This intervention was partially supported by citizen's donations. The acquired farms have been rented to local farmers on the condition of their compliance with strict regulations related to the protection of steppic bird species. The nature conservation activities of this NGO in the Municipality of Castro Verde have been disseminated by the Portuguese media, namely in TV programs and in national newspapers.
Landscape value elicitation was a two stage process which allowed controlling for the effect of increasing information on the good being valued. In the first stage of the elicitation procedure, the existence and dependence of birds on the current landscape structure was omitted. At this stage information provided to respondents was restricted to a location map, a set of pictures depicting the landscape units and a verbal description of their origin and current management. In the second stage, information about the birds, namely their conservation status, was provided. At this point the respondents had the opportunity to revise one or both WTP amounts stated earlier.

The open-ended question format was used to elicit the value of landscape scenery and its role in bird species conservation. The elicitation question format is one of the controversial aspects of the contingent valuation method. The discussion has been focused on the effects of adopting an open-ended or a dichotomous (closed) format in revealing the respondents' true willingness to pay. Although there is extensive literature on the topic (Reaves et al., 1999; Cameron et al., 2002) no single elicitation format has proved to be the ideal, all of them exhibiting advantages and disadvantages.

The use of open-ended questions in eliciting environmental goods became less frequent in contingent valuation after Arrow et al. (1993). Following the panel's recommendations on the use of the dichotomous format this elicitation technique gained prominence among CV practitioners. Nevertheless open-ended formats have some advantages, namely when there is scarce information about individuals' valuation of the elicited good. Missing such information, the use of closed elicitation formats becomes impracticable due to difficulty in designing the appropriate bid-vector to proceed with the elicitation in a closed format. Moreover, open-ended formats are also known for their conservative estimates (Pruckner, 1995; Brown et al., 1996) and avoidance of starting point bias (O'Conor et al., 1999; Carlsson and Johansson-Stenman, 2000).

The contingent valuation questions were preceded in the questionnaire by a remark reminding respondents of their own budget income, their current expenses and the existence of other typical rural landscapes in the country.

\subsection{The in-person survey}

The interviewers were four researchers from the Department of Botany of the University of Coimbra that are familiar with the contingent valuation methodology and with the theme of the present study.

The interviews always began with a spoken introduction provided by the interviewer, consisting of a short explanation on the nature of the research and a short description of the problem being addressed. At that stage individuals were asked for their interest in participating in the study. The wording of this survey introduction can be reproduced as:

"Good Morning Madam/Sir: We are researchers at the University of Coimbra and we are conducting a research project which aims to investigate possible options for future strategies of conservation and management of rural landscapes. The target landscape of our study is the Cereal Steppe of Castro Verde that is dominant in the Munici- 
pality of Castro Verde. For this purpose we would like to get your opinion by answering our questionnaire".

We started by recruiting participants among pedestrians in the main commercial streets in different regions of the country. After several attempts to carry out the interviews we realized that people did not desire to be interrupted in their daily routine and those who accepted to participate concluded during the interview that they would need more time to think about it. Facing this, the survey strategy "was moved from the streets to the beach" and was carried out during July and August of $2001 .^{5}$ In this period a large percentage of the Portuguese population is on vacation and beaches are the favorite destinations. With this survey strategy, the response rate was highly increased and people paid more attention to the questions and the level of reflection on the market scenarios, and the subject in general, was improved. Concerning the sampling selection procedure, only those very young looking individuals were not considered as potential participants (because we were interested in individuals with an income). Whenever individuals were in a group (a family for instance) only one of them was approached and invited to participate in the survey. The number of individuals interviewed at each beach site was mainly determined by the time allocated to that site. It should be underlined that the interviews were conducted at different (geographically) beach sites pursuing the objective of getting a sample as heterogeneous as possible and hence time was often the determinant of the number of interviews conducted at each sampling site.

\subsection{The Internet survey}

Internet surveys can be conducted using both electronic mail (e-mail) and the World Wide Web (Web). In the former case the survey instrument is embedded in the e-mail message body or attached to the e-mail message. In the latter, the survey instrument is hosted on a web site and is reached by respondents either by following an e-mail message link or a link provided in another web site, e.g. a popular search engine (Fricker and Schonlau, 2002). We used the second type of Internet surveys since we were interested in providing Internet survey participants with the same visual materials used for in-person interviewing. Currently, and although software availability to overcome some inherent limitations to the use of electronic mail is increasing, electronic mail surveys are still less powerful than web posted surveys. Electronic mail surveys are in general restricted to text messages and make it difficult to use visual materials and appealing designs (Schonlau et al., 2001; Andrews et al., 2003).

In our web based survey, the electronic questionnaire was hosted at the homepage of our research institute at the University of Coimbra and electronic mail was used to disseminate the electronic questionnaire ${ }^{6}$ by including in the e-mail message body a link to the questionnaire website.

\footnotetext{
${ }^{5}$ The data from the street survey approach was removed from any further analysis.

${ }^{6}$ This procedure is a generally cheaper alternative to advertise the survey in prominent websites.
}

Survey participants were recruited among Telepac ${ }^{7}$ Internet service subscribers. The e-mail address of participants was obtained from the Telepac client directory using the search tool available at http://www.clicknet.pt. Among the searching options the entry name was considered the most neutral for our purpose. A total of 4035 different e-mail addresses was found by using an unsystematic list of surnames as search entry. We mainly used the surnames of the staff of our department. At each search attempt a maximum of one hundred of records is provided by the searching tool. Each surname was entered only once and the records obtained in each search attempt were screened to eliminate repeated e-mail addresses. ${ }^{8}$

An invitation letter introducing the scope of the survey and relevant information to participants such as anonymity, personal data confidentiality and questionnaire website security was sent to all the e-mail addresses selected as described above. The subject line reading of the e-mail message was survey. An e-mail message personalization procedure, as suggested by Schaefer and Dillman (1998), was adopted by using the e-mail "Bcc:" field. Using Bcc - blind carbon copy - it seems that the email message has been sent directly to individual respondents. This is said to improve the probability of adhesion since individuals will consider themselves special. Also, its use ensures confidentiality of e-mail addresses and prevents respondents from responding to other recipients of the survey. The web survey questionnaire was created using HTML software and its structure, including the ordering and contents of questions, was similar to that used for in-person interviewing. The whole questionnaire appeared on a single page and the respondent moved up and down by means of the scroll bar, on the right-hand side of the browser. The questionnaire contained text entry boxes, with wrapping and scrolling, not single-line entry, for open-ended questions. Drop-down menus were used for the respondent's municipality choice and radio buttons ${ }^{9}$ for the remaining multiple choice questions. The respondents participation in the survey ended once they pressed the submit button at the end of the questionnaire.

The responses introduced by the participants were transmitted via HTTP forms and processed by a program in Visual Basic which sent them by e-mail to the researcher. Results were then imported into a Microsoft Excel spreadsheet.

A common problem with web based surveys is that any one can reach the electronic questionnaire, even those who have not been invited to do it. The risk is that the same individual can fill in the questionnaire as many times as he want, thus distorting the results. This can be avoided by adopting a control mechanism, such as requiring respondents to accept a "cookie" 10 prior to take the survey or by adopting a password

\footnotetext{
7 Telepac, SA is the leading Internet service provider in Portugal.

8 Typically each individual has more than one surname, making it possible to include repeated subjects in our participants' mailing list. The inclusion of repeated subjects was avoided by eliminating all the records that contained one of the surnames used in a previous search attempt.

${ }^{9}$ Similar to the tick boxes in paper questionnaires. All options are visible on the screen. Only one answer could be selected. Useful when there are few possible responses.

10 The main purpose of cookies is to identify users. By themselves, cookies are a pretty simple way to save information from one session to another.
} 


\begin{tabular}{|c|c|c|}
\hline & Web based & In person \\
\hline & $(n=192)$ & $(n=230)$ \\
\hline \multicolumn{3}{|l|}{ Age } \\
\hline $21-30$ & 40.6 & 17.4 \\
\hline $31-40$ & 31.3 & 30.4 \\
\hline $41-50$ & 17.2 & 25.7 \\
\hline $51-60$ & 7.3 & 15.7 \\
\hline$>60$ & 3.6 & 10.9 \\
\hline \multicolumn{3}{|l|}{ Gender } \\
\hline Female & 35.9 & 39.6 \\
\hline \multicolumn{3}{|l|}{ Education } \\
\hline Primary school $(Y=4)$ & 0 & 12.6 \\
\hline Basic school $(Y=9)$ & 1.0 & 12.2 \\
\hline Secondary school $(Y=12)$ & 26.6 & 40.0 \\
\hline University $(\mathrm{Y}=16)$ & 72.4 & 35.2 \\
\hline \multicolumn{3}{|l|}{ Income $^{a}$} \\
\hline $0-500 €$ & 13.0 & 23.0 \\
\hline $500-1000 €$ & 30.2 & 42.6 \\
\hline $1100-1750 €$ & 29.2 & 21.3 \\
\hline$>1750 €$ & 27.6 & 13.0 \\
\hline
\end{tabular}

protection procedure. We used the server log files ${ }^{11}$ to detect and account for multiple submissions through the visitor's IP $^{12}$ number.

\section{Results and discussion}

\subsection{Samples' socio-demographics}

Table 1 displays the socio-demographics of both samples. The Internet sample is largely represented by individuals under forty years old (72\%) while in the in-person sample these individuals only represent about $59 \%$ of the respondents. Also the respondents who submitted a questionnaire through the Internet are better educated (99\% received at least twelve years of education) than those interviewed in-person. Both samples are overrepresented by males. Concerning the distribution of income it was found that higher income classes are more represented in the web based sample.

\subsection{Response rate}

A total of 230 in-person interviews were completed during the survey, out of 275 attempts, ${ }^{13}$ leading to a survey response rate of $84 \%$. It is important to point out, when comparing the response rate between survey modes, that no cases of giving up were registered when respondents were

\footnotetext{
${ }^{11}$ Log files are records of web server activity. They provide details about file requests to a server and the server response to those requests.

${ }^{12}$ To every computer that communicates over the Internet is assigned an IP address that uniquely identifies the device and distinguishes it from other computers on the Internet.

${ }^{13}$ This number refers to those who declined to participate in the survey after having been informed about the scope of the study.
}

interviewed in person, i.e., all those who accepted to participate in the survey completed the questionnaire (in the web based survey a total of 53 questionnaires were submitted uncompleted, see Table 2). Concerning the web based survey, from a total of $3785^{14}$ e-mail messages that were successfully sent, a total of 192 usable (completed) questionnaires were received, a survey response rate of $5.1 \%$ (Table 2).

The observed response rate differences are not surprising. Contingent valuation surveys based on in-person interviews are characterized by higher response rates than other self completed, mail based surveys. Mannesto and Loomis (1991), when evaluating the suitability of mail versus in-person surveys, found a $97 \%$ completion rate for in-person interviewing and a response rate of $24 \%$ for mail survey. Bateman et al. (1992), in eliciting the recreational value of a wetland in the UK, reported a mail survey response rate of $30 \%$ and an inperson response rate of $78 \%$. The web based survey response rate obtained in our study is lower than the values reported in the literature. Based on the studies' review by Schonlau et al. (2001) the response rate of web based surveys that used email to contact participants, and the web as the response mode, ranges from $19 \%$ to $62 \%$. Currently there is a common consensus on the positive effect of multiple contacts on the response rate of self-administered surveys. The response rate of $5.1 \%$ obtained in our web based survey probably reflects the absence of these follow up contacts.

\subsection{Information additivity effects}

In the first stage of the valuation process, respondents were asked about their WTP, as an annual tax and as a voluntary contribution (one time payment). At this stage, respondents were informed about the landscape location and the area occupied within the Municipality of Castro Verde. A set of pictures illustrating landscape scenery was shown.

The effect of adding information on respondents' WTP was tested by asking respondents to revise their early bid after being informed about the assemblage of birds relying on the current landscape structure and their conservation status at the global scale. Birds' pictures, identified by their scientific and common names, were also provided. Individuals' reasons for not revising their earlier bids were collected in a follow up question.

Of the 230 individuals interviewed in person, 13\% (31 cases) revised their previous WTP as voluntary contribution (VC) and $12 \%$ (27 cases) revised their WTP as a governmental tax (TAX). In the web based survey, a smaller percentage of changes was reported. A total of $8.0 \%$ (17 cases) and 5.0\% (10 cases) of the respondents incremented their WTP as voluntary contribution and governmental tax, respectively. We should be aware that,

\footnotetext{
14 This number is assumed to be the web based equivalent to the 275 attempts reported for the in-person survey. There is a potential error with this assumption since an unknown number of participants could have rejected the e-mail message before reading its contents. From it can be concluded that our web based response rate of $5.1 \%$ is the lower bound for estimation of the survey response rate.
} 


\begin{tabular}{lr}
\hline Table 2 - Survey statistics and response rate \\
\hline Web based \\
\hline Number of e-mails attempted & 4035 \\
Number of bounced e-mails ${ }^{\text {a }}$ & 250 \\
Number of successfully e-mails delivered & 3785 \\
Number of E-questionnaires received & 265 \\
$\quad$ E-questionnaires not complete & 53 \\
$\quad$ E-questionnaires completed & 192 \\
Response rate ${ }^{\text {b }} \%$ & 5.1 \\
& \\
In person & 275 \\
\hline Number of interviews attempted & 230 \\
Number of interviews completed & 83.6 \\
Response rate (\%) & \\
\hline a E-mail that is returned back to the server that sent it (e.g. due to \\
an invalid address). \\
b Calculated as the number of e-mails successfully sent divided by \\
the number of completed e-mails received. \\
\hline
\end{tabular}

in the case of the web based survey, the respondents may have read the entire questionnaire first, apprehending the context of what was being asked, and only afterwards answering the questions. If that was the case, it would, per se, justify the lower percentage of respondents who revised their bids. This methodological caveat, the absence of control for questions sequencing, would have been avoided if an interactive format had been adopted instead for presenting the survey in a single webpage. In an interactive format questions are presented to respondents screen by screen and in order to proceed to a new question (new screen) the respondent needs to submit the previous one. In this way, the respondent is obliged to strictly follow the sequence of questions as intended by the researcher. Nevertheless, and particularly if sequence is not a concern, presenting all the questionnaire in a single webpage allows respondents to easily determine the length of the questionnaire (this aspect is of particular importance because people would like to know how time consuming is the interview). If the interactive format is adopted for presenting the questionnaire a progress indicator must be used to inform respondents about how much of the questionnaire remains to be completed.

The statistical significance of the observed differences in the stated WTP amounts, before (Tax1 and VC1) and after (Tax2 and VC2) having provided additional information about the landscape, namely the birds' existence, was investigated through paired comparisons. The null hypothesis that the stated amount, either as governmental tax or as voluntary contribution, was the same in both stages of the valuation was rejected based on the outcome of the Wilcoxon Signed Ranks Test $(p<0.05)$, and this was true both for the respondents who submitted the questionnaire through the web and for the respondents interviewed in person (in-person survey: Tax2Tax1: $Z=-4.551, p<0.05$; VC2-VC1: $Z=-4.865, p<0.05$. Web based survey: Tax2-Tax1: $Z=-2.810, p=0.05$; VC2-VC1: $Z=$ $-3.630, p<0.05$ ). This finding is consistent with economic theory: one would expect WTP for environmental goods to vary with information, as for market goods. Additional evidence of consumers' attitude towards the valuation process was inferred through the analysis of responses to the open-ended follow up question on motives for the maintenance of earlier bids. The most common argument for not revising earlier bids was "I already knew about it [birds]", and it holds for both survey types. This apparent familiarity of respondents with the good being elicited is supported by the proportion of respondents that had already visited the study area $(60 \%$ of in-person respondents and $74 \%$ of the Internet respondents).

\subsection{Respondents' attitude towards payment: payers us non-payers}

Respondents were asked to state their WTP to preserve the Cereal Steppe of Castro Verde as an annual governmental tax (TAX) and as a voluntary contribution (VC). We observed that, in spite of the payment vehicle choice given to respondents, a large proportion of zero bids were stated, $36 \%$ of respondents surveyed in person and $33 \%$ of those sampled through the web. The attitude towards paying splits the samples into two groups: Payers and Non-payers. Payers refer to those who have accepted to pay any money amount, at least through one of the payment vehicles used in the contingent valuation questions. Those who declined to pay at all were called Non-payers.

A Chi-square test was used for statistical inference on the independence of the respondents' attitude towards paying and the survey mode. Based on the test outcome it is very unlikely that the variables were related $\left(\chi^{2}=0.269, d f=1\right.$ and $p=0.604)$, i.e., there is no relationship between respondents' attitude towards payment and survey mode.

Respondents' attitude towards payment is also not likely to have been determined by the nature of the payment vehicles offered: only a small percentage of respondents who accepted to pay exhibited payment vehicle preference (Fig. 1). Analysis of the in-person sample revealed that no more than $10 \%(23$ cases) refused to pay through a governmental tax and 9.1\% (21 cases) considered the governmental tax a fair payment mechanism. In the web sample, the proportions were even

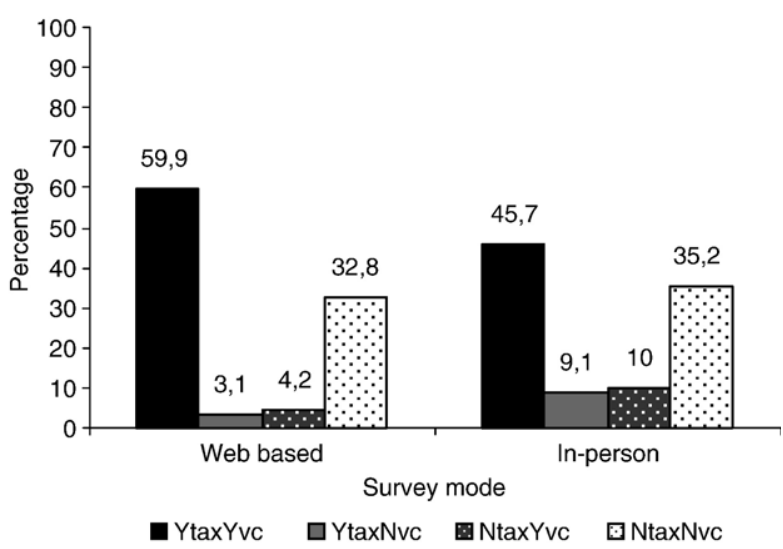

Fig. 1-Acceptance of payment vehicles in both survey modes. $\mathrm{Y}$ denotes $\mathrm{Yes}$ and $\mathrm{N}$ denotes No. tax abbreviates annual governmental tax and vc refers to voluntary contribution (one time payment). 
smaller: $4.2 \%$ (8 cases) and 3.1\% (6 cases) of the respondents refused to pay through a governmental tax and a voluntary contribution, respectively.

\subsubsection{Zero bids and protest responses analysis}

Distinction between true (or genuine) zero bids and protest responses used the same criteria as Brower and Slangen (1998): protest responses occurred when respondents stated a zero bid, even though the environmental good in question had a positive value for them and they were not prevented from paying by an income constraint. Thus, in our case, and since we used a two stage elicitation format, to consider a zero bidder as a protester two conditions should hold:

a) Tax and voluntary contribution zero bid was stated in both stages of the valuation;

b) In any of the valuation stages, none of the following arguments were given: budget income constraint or the good is worth nothing.

Based on this selection procedure, a total of 68 respondents, surveyed in person, were identified as protesters among the zero bidders (84\%) and, within the web based surveyed respondents, we found a total of 58 protesters, representing $92 \%$ of the reported zero bids (Table 3 ). Based on the chi-square test outcome we did not find statistical evidence that survey mode and the occurrence of any of the zero bid types were related ( $p=0.93$, true zero bid; $p=0.88$, protest).

Protest responses were grouped in six categories (Table 4). Protest 1, Protest 2, and Protest 5, were defined by respondents' beliefs about who should pay to preserve the Cereal Steppe and, thus, why they thought it was unfair to ask them to pay. Protest 1 and Protest 2 were considered distinct because there was a group of respondents who explicitly stated the existence of other landscapes for which government intervention is also expected. Protest 3 and 4 were identified by respondent's dissention in regard to the programs. The last protest category (Others) refers to less structured protests, which proved difficult to analyse. The protest category frequencies for each survey mode as well as the results of a series of chi-square tests of independence for each protest category by survey mode are presented in Table 4. Based on the chi-square tests we conclude that a statistically significant relationship between protest category and survey mode was found only for Protest 2 and Protest $5(p<0.05)$. Protest 5 was more likely to be found among those interviewed in person while Protest 2 was more frequent among

Table 3 - Proportions of true zero bids and protests in both samples

\begin{tabular}{lcclll} 
& Web based & & In person & $\chi^{2}$ \\
\cline { 2 - 2 } & $(n=192)$ & & $(n=230)$ & & \\
\hline Zero bidders & $63(32.8 \%)$ & & $81(35.2 \%)$ & & \\
True zero bids & $4(2.1 \%)$ & & $12(5.2 \%)$ & 2.818 & $p=0.93$ \\
Protest bids & $58(30.2 \%)$ & & $68(29.6 \%)$ & 0.021 & $p=0.88$ \\
\hline
\end{tabular}

Note: Values in parentheses are percentages of the total sample; in each sample one missing response to the follow up question was found.

\begin{tabular}{|c|c|c|c|c|}
\hline \multirow[t]{2}{*}{$\begin{array}{l}\text { Protest } \\
\text { code }\end{array}$} & \multirow[t]{2}{*}{ Description } & $\begin{array}{c}\text { Web } \\
\text { based }\end{array}$ & $\begin{array}{c}\text { In } \\
\text { person }\end{array}$ & $\chi^{2}$ \\
\hline & & $(n=58)$ & $(n=68)$ & \\
\hline 1 & $\begin{array}{l}\text { To preserve the Cereal Steppe } \\
\text { of Castro Verde is a } \\
\text { governmental task and should } \\
\text { be done using the existing } \\
\text { revenues. }\end{array}$ & $\begin{array}{l}35 \\
(60)\end{array}$ & $\begin{array}{l}40 \\
(59)\end{array}$ & 0.030 \\
\hline 2 & $\begin{array}{l}\text { There are other rural } \\
\text { landscapes in Portugal whose } \\
\text { protection is needed for } \\
\text { similar reasons. The } \\
\text { preservation of all of them, } \\
\text { including the Cereal Steppe of } \\
\text { Castro Verde, is a } \\
\text { governmental task and should } \\
\text { be done using the existing } \\
\text { revenues. }\end{array}$ & $\begin{array}{c}8 \\
(14)\end{array}$ & $\begin{array}{c}1 \\
(2)\end{array}$ & $7.166^{*}$ \\
\hline 3 & $\begin{array}{l}\text { Programs would not work } \\
\text { even if the money were given. } \\
\text { Do not believe that the money } \\
\text { collected will be used for this } \\
\text { purpose. }\end{array}$ & $\begin{array}{c}2 \\
(3)\end{array}$ & $\begin{array}{l}3 \\
(4)\end{array}$ & 0.076 \\
\hline 4 & $\begin{array}{l}\text { Programs do not ensure long } \\
\text { term local rural ecological and } \\
\text { economic sustainability. }\end{array}$ & $\begin{array}{c}11 \\
(19)\end{array}$ & $\begin{array}{c}10 \\
(15)\end{array}$ & 0.409 \\
\hline 5 & $\begin{array}{l}\text { Local people should pay to } \\
\text { preserve it. }\end{array}$ & $\begin{array}{c}1 \\
(2)\end{array}$ & $\begin{array}{c}9 \\
(13)\end{array}$ & $5.677^{*}$ \\
\hline 6 & Other & $\begin{array}{c}1 \\
(2)\end{array}$ & $\begin{array}{c}5 \\
(7)\end{array}$ & \\
\hline
\end{tabular}

Note: Values in parentheses are the percentage of the number of protests.

* $p<0.05$.

those interviewed through the web. Dependence of the remaining protest categories on the survey mode was not statistically significant $(p>0.05)$.

The higher frequency of Protest 2 among those who submit a questionnaire through the web may support the idea that self-administered surveys are more likely to provide respondents with plenty of time to think about the valuation context. In our case, the existence of other typical landscapes across the whole country, for which conservation schemes are also intended, was essentially brought into the valuation exercise by those interviewed through the web. Differences in respondents' perception of valuation context due to interview settings (time of interviews and information) have been reported in the literature as an argument against in-person interviews (Macmillan et al., 2002).

\subsection{Survey mode effect on mean WTP}

In Table 5 we present the arithmetic mean, and other associated statistics, for the populations of WTP values for each survey mode, both as annual tax and one time donation. The reported values are those obtained in the first stage of landscape elicitation. Although the arguments for no rectification of the earliest stated WTP values do not suggest that adding up information effects were observed (see Section 4.3), the changes in 


\section{Table 5 - Sub-samples mean WTP and associated statistics}

Management scenarios

\begin{tabular}{llll} 
Survey mode & Statistics & $\begin{array}{l}\text { Government intervention } \\
\text { Annual tax } \\
2 / 3 \text { of the area of the Municipality of } \\
\text { Castro Verde }\end{array}$ & $\begin{array}{l}\text { Environmental NGO intervention } \\
\text { One time donation } \\
1 / 3 \text { of the area of the Municipality of } \\
\text { Castro Verde }\end{array}$ \\
\cline { 2 - 3 } Web based $(\mathrm{N}=192)$ & 37 & 36 \\
& Percentage of zero values & 39 & 71 \\
& Arithmetic mean & 0.5 & 0.5 \\
& Minimum & 498 & 1496 \\
& Maximum & 29 & 48 \\
In person $(\mathrm{N}=230)$ & Spike adjusted mean & 50 & 47 \\
& Percentage of zero values & 92 & 107 \\
& Arithmetic mean & 0.5 & 0.5 \\
& Minimum & 1197 & 1197 \\
& Maximum & 47 & 57 \\
\hline
\end{tabular}

Note: Money amounts are reported in Euros.
WTP values were found to be statistically significant. Thus, in order to keep WTP estimates as conservative as possible, as recommended by the NOAA panel, we have used for the purpose of mean samples estimation (and associated statistics) the values observed in the first stage elicitation. The arithmetic means for the WTP collected as annual tax were estimated as 38.65 and $91.6 €$, respectively for the web based and in-person sub-samples. For the case of one time payment donation the arithmetic means of WTP were estimated as 70.9 and $107.3 €$, respectively for the web based and in-person sub-samples. Since all the four subpopulations have a large mass of data centered on zero, and a continuous positive distribution of WTP amounts, exact calculations of mean WTP values require econometric treatment. Hence, in a comparison paper (MartaPedroso et al., submitted for publication) we used the spike adjusted model, as proposed by Reiser and Shechter (1999). The spike adjusted mean was calculated as the probability of having a positive WTP multiplied by the mean WTP for those who expressed a positive WTP (assuming a log normal distribution). The annual tax spike adjusted mean was estimated as 29.4 for the web based sub-sample and as $47.3 €$ for the case of in-person sub-sample. For the one time payment the spike adjusted mean was found to be 48.2 for the web based and $56.9 €$ for the inperson sub-samples, respectively.

The differences in mean WTP values between sub-samples defined by the survey mode may suggest that respondents surveyed through the web are more likely to state lower WTP amounts than those interviewed in person.

Marta-Pedroso et al. (submitted for publication) provide statistical evidence, for the case of one time payment donation, that the positive stated amount is determined by the individual income, having a positive effect, and that the probability of obtaining a zero WTP value is not related with the survey mode.

\section{Conclusions}

We have found, in the context of contingent valuation surveys, that when a single e-mail invitation is sent to potential participants the response rate is much lower than the one obtained in surveys conducted through in-person interviews. Nevertheless delivering the survey through the Internet is much less costly.

Concerning the other critical aspects of the contingent valuation method we did not obtain empirical evidence that web based surveys are more susceptible to information additivity effects than surveys conducted in person. We have also found that the proportion of zero bids is similar in both survey samples. The analysis of the respondents' arguments for not paying for the preservation of the cereal steppe of Castro Verde revealed that a large percentage of the zero WTP values observed in both samples were protests. Our findings also indicate that web based surveys generate more conservative estimates than in-person interviewing (these differences were observed for both payment types used in our experiment).

We conclude that the use of web based surveys is promising in the context of contingent valuation. Currently, its use in general population surveys is still discouraging due to difficulties in drawing probability based representative samples. However, since web based surveys are enormously cheaper than in-person surveys, and also because available statistics provide evidence that the number of Internet users in Portugal is increasing, we do think that further research efforts to optimize their performance are needed. The effect of multiple contacts on survey response rate is clearly an aspect which needs to be tested.

\section{Acknowledgments}

This work was supported by the Fundação para a Ciência e Tecnologia (FCT), through grants PRAXIS XXI/BD/19742/99 and SFRH/BPD/24416/2005 (C. Marta-Pedroso) by the Life Program of the European Commission through project EXTENSITY Environmental and Sustainability Management Systems in Extensive Agriculture, LIFE03 ENV/P/000505.

We would like to thank the anonymous referees for their comments and valuable suggestions. 
Appendix A. Management scenarios and contingent valuation questions

\section{Question 9) [landscape pictures and location maps]}

The Cereal Steppe of Castro Verde is originated by traditional winter cereals cultivation. The cereal steppe is the main landscape unit within the Municipality of Castro Verde, Southern Portugal, corresponding to about $82 \%$ of the area used for agriculture in the Municipality. Structurally the cereal steppe is an open mosaic landscape (with a very low tree density) consisting mainly of cereal fields, stubble, ploughed and fallow land (usually grazed). Economically this agricultural system is marginal.

This agricultural system has been subsidized by the European Union in the last years within the scope of the agri-environmental measures. The goal was compensating financially those farmers who keep their land under extensive cereal cultivation.

Imagine that this financial support is to be suspended and other farming options (e.g. agro-forestry), would take place leading to a strong change in landscape structure. Regarding this I would like to ask you to consider the following management scenarios that would, if implemented, lead to the preservation of the current landscape structure:

A) As part of a national strategy for rural landscapes preservation the Portuguese government might implement a program of financial incentives to which the farmers of the municipality of Castro Verde could apply.

The objective of such financial support would be to ensure the continuity of the traditional agricultural practices, as a strategy for preserving the cereal steppe at least in $2 / 3$ of the area of the municipality of Castro Verde.

This investment would be partially supported by a TAX to be paid by all Portuguese. Suppose that the tax, additional to your current taxes, will be managed honestly and will be totally allocated to maintain the traditional agricultural practice that originate the cereal steppe.

What is the maximum that you would be willing to pay annually, as an environmental tax, to maintain the cereal steppe, at least in $2 / 3$ of the area of the municipality of Castro Verde.

B) In order to maintain the current landscape, at least in 1/3 of its extension, a private and nonprofit organization would acquire that area in Castro Verde and would be responsible for its management. This intervention would be fundamentally supported by citizens' donations.

What is the maximum that you would be willing to pay, as a one time payment, to maintain the Cereal steppe, at least in $1 / 3$ of the area of the municipality of Castro Verde?

If you would not be willing to pay anything please explain why. 


\section{Question 10) [birds' pictures and information on their habitat requirements]}

The landscape introduced to you before is from an ecological perspective an important refuge for a set of bird species threatened at national and international level. Eventual landscape transformations, arising from a shift in agricultural practice, will lead to a reduction in the populations of these birds and contribute to the risk of their extinction at the global scale.

\section{Facing this information would you like to revise the amount stated before?}

Yes $\square$ Correction of answer 9A

Correction of answer 9B
No, I already knew it

No, I do not consider it important

No, other $\quad$ Please explain

English translation of the valuation section of the contingent valuation questionnaire

\section{R E F E R E N C E S}

Andrews, D., Nonnecke, B., Preece, J., 2003. Electronic survey methodology: a case study in reaching hard-to-involve internet users. International Journal of Human-Computer Interaction 16 (2), 185-210.

Arlinghaus, R., Mehner, T., 2004. Testing the reliability and construct validity of a simple and inexpensive procedure to measure the use value of recreational fishing. Fisheries Management and Ecology 11, 61-64.

Arrow, K., Solow, R., Portney, P.R., Leamer, E.E., Radner, R., Schuman, H., 1993. Report of the NOAA Panel on contingent valuation. Federal Register 58 (10), 4601-4614.

Bateman, I.J., Mawby, J., 2004. First impressions count: interviewer appearance and information effects in stated preference studies. Ecological Economics 49, 47-55.

Bateman, I.J., Willis, K.G., Garrod, G.D., Doktor, P., Langford, I., Turner, R.K., 1992. Recreation and environmental preservation value of the Norfolk Broads: a contingent valuation study. Report to the National Rivers Authority, Environmental Appraisal Group. University of East Anglia.

Berrens, R.P., Bohara, A.K., Jenkins-Smith, H.C., Silva, C.L., Weimer, D.L., 2004. Information and effort in contingent valuation surveys: application to global climate change using national internet samples. Journal of Environmental Economics and Management 47, 331-363.

Boxall, C.P., Adamowicz, W.L., Swait, J., Williams, M., Louviere, J., 1996. A comparison of stated preferences methods for environmental valuation. Ecological Economics 18, 243-253.

Brower, R., Slangen, L.H.G., 1998. Contingent valuation of the public benefits of agricultural wildlife management: the case of Dutch peat meadow land. European Review of Agricultural Economics 25, 53-72.

Brown, T.C., Champ, P.A., Bishop, R.C., 1996. Which response format reveals the truth about donations to a public good. Land Economics 72 (2), 152-166.

Cameron, T.A., Poe, G.L., Ethier, R.G., Schulze, W.D., 2002. Alternative non-market value-elicitation methods: are the underlying preferences the same? Journal of Environmental Economics and Management 44 (3), 391-425.

Carlsson, F., Johansson-Stenman, O., 2000. Willingness to pay for improved air quality in Sweden. Applied Economics 32 (6), 661-669.
Carson, R.T., 2000. Contingent valuation: a user's guide. Environmental Science and Technology 34 (8), 1413-1418.

Delgado, A., Moreira, F., 2000. Bird assemblages of an Iberian cereal steppe. Agriculture, Ecosystems and Environment 78, 65-76.

Fricker, D.F., Schonlau, M., 2002. Advantages and disadvantages of internet research surveys: evidence from the literature. Field Methods 14 (4), 347-367.

Hudson, D., Seah, L., Hite, D., Haab, T., 2004. Telephone presurveys, self-selection, and non-response bias to mail and internet surveys in economic research. Applied Economics Letters 11, 237-240.

Jackobsson, K.M., Dragun, A.K., 1996. Contingent valuation and endangered species: methodological issues and applications. Edward Elgar, Cheltenham.

Kaplowitz, M.D., Hadlock, T.D., Levine, R., 2004. A comparison of web and mail survey response rates. Public Opinion Quarterly 68 (1), 94-101.

Leggett, C.G., Kleckner, N.S., Boyle, K.J., Duffield, J.W., Mitchell, R.C., 2003. Social desirability bias in contingent valuation surveys administration through in-person interviews. Land Economics 79 (4), 561-575.

Lenert, L.A., 2003. Use of willingness to pay to study values for pharmacotherapies for migraine headache. Medical Care 41 (2), 299-308.

Loureiro, M., Lotade, J., 2005. Interviewer effects on the valuation of goods with ethical and environmental attributes. Environmental and Resource Economics 30 (1), 49-72.

Macmillan, D.C., Philip, L., Hanley, N., Alvarez-Farizo, B., 2002. Valuing the non-market benefits of wild goose conservation: a comparison of interview and group-based approaches. Ecological Economics 43, 49-59.

Mannesto, G., Loomis, J.B., 1991. Evaluation of mail and inperson contingent value surveys: results of a study of recreational boaters. Journal of Environmental Management 32, 177-190.

Marta-Pedroso, C., Freitas, H., Domingos, T., de Groot, R.S., Gort, G., submitted for publication. Econometric estimation of the willingness to pay to preserve the Cereal Steppe of Castro Verde (Southern Portugal). Environmetrics.

O'Conor, R.M., Johannesson, M., Johansson, P.-O., 1999. Stated preferences, real behaviour and anchoring: some empirical evidence. Environmental and Resource Economics 13 (2), 235-248. 
Pruckner, G.J., 1995. Agricultural landscape cultivation in Austria: an application of the CVM. European Review of Agricultural Economics 22 (2), 173-190.

Reaves, D.W., Kramer, R.A., Holmes, T.P., 1999. Does question format matter? Valuing an endangered species. Environmental and Resource Economics 14, 365-383.

Reiser, B., Shechter, M., 1999. Incorporating zero values in the economic valuation of environmental program benefits. Environmetrics 10, 87-101.

Schaefer, D., Dillman, D., 1998. Development of a standard e-mail methodology: results of an experiment. Public Opinion Quarterly 62, 378-397.

Schonlau, M., Fricker Jr., R.D., Elliott, M.N., 2001. Internet survey case studies. Conducting Research Surveys via E-mail and the
Web. RAND Publications. Available at: [http://www.rand.org/ publications/MR/MR1480/MR1480.ch6.pdf].

Suárez, F., Navesco, M.A., De Juana, E., 1997. Farming in the drylands of Spain: birds of the pseudosteppes. In: Pain, D.J., Pienkowski, M.W. (Eds.), Farming and Birds in Europe - The Common Agricultural Policy and its Implications for Bird Conservation. Academic Press, San Diego, pp. 297-330.

Tsuge, T., Washida, T., 2003. Economic valuation of the Seto Inland Sea using an internet CV survey. Marine Pollution Bulletin 47, 230-236.

Tucker, G.M., Heath, M.F., 1994. Birds in Europe: Their Conservation Status. Birdlife International, Cambridge.

Venkatachalam, L., 2004. The Contingent Valuation Method: a review. Environmental Impact Assessment Review 24 (1), 89-124. 